\title{
Height and health: predicting longevity from bone length in archaeological remains
}

\author{
D Gunnell, J Rogers, P Dieppe
}

Contemporary studies show that taller people live longer. ${ }^{12}$ Short stature is particularly associated with an increased risk of cardiovascular and respiratory mortality. ${ }^{2}$ It is uncertain whether this association existed in earlier generations, when disease patterns were quite different. Before the 19th century the main causes of death were infection, malnutrition, accidents and childbirth. Here we report an analysis of the association between bone length, a marker of stature, and age at death based on the skeletal remains of 490 subjects obtained from an archaeological investigation in Barton on Humber. Our aim was to determine whether height-mortality associations existed in earlier generations.

\section{Methods}

SOURCE OF SKELETAL REMAINS

The skeletal material was derived from an excavation of approximately 3000 skeletons at the site of St Peter's Church, Barton on Humber in the north east of England. The graves date from the 9 th century up to around 1850 . The lengths of all available long bones were measured to the nearest millimetre using an osteometric board, by two trained observers. Sex and age at death were assigned to skeletons using standard anthropological methods. Sex, based on morphological differences mainly in the pelvis but also in the skull and post-cranial bones, can be assigned with some confidence. ${ }^{34}$ Aging adult remains is more problematic and in this sample was mainly based on an assessment of changes in the pubic symphisis and the amount of wear to dentition. Over the age of 45 it is not usually possible to reliably divide into further age categories. ${ }^{45}$

SAMPLE USED IN THIS ANALYSIS

Around a third of the 3000 skeletons belonged to children and adolescents (aged <20). Because bone growth is incomplete before adulthood our analysis was restricted to those aged 20 years or over at the time of death, as by this age $96 \%-100 \%$ of adult height has been attained. A further $50 \%$ of adults could not be sexed because of non-survival of body parts, their remains have been excluded from this analysis because of the well recognised sex differences in body size and mortality patterns. Other subjects were excluded because there were no remaining intact long bones or because it was not possible to estimate when they were buried or their age of death. These factors reduced the number of skeletal remains available for this analysis to 490. We have no reason to believe that sample attrition as described above will bias our results.

STATISTICAL ANALYSES

Analyses are based on the remains of adults to whom it was possible to assign sex and age at death. Associations between long bone length (femur, tibia, fibula, humerus, ulna and radius) and mortality were examined using two logistic regression models, one using the estimated age at death as $<30$ years as the cut point for premature mortality, the other using $<45$ years. To control for the possible confounding effects of secular increases in height, a five level variable indicating the period when the subject was buried was included in all models-burial dates were categorised into 200 year bands. We included a term for sex in all models. To enable us both to compare the strength of associations with different bones and to allow us to produce a pooled estimate of relative bone length for each subject we converted all long bone lengths to sex specific standard deviation ( $\mathrm{z}$ ) scores. Where two of the same bones (for example, two femurs) were available for one skeleton the mean of the two bone lengths was used. For each subject we also generated a mean of the $\mathrm{z}$ scores for all the available arm

ase (or decrease) in premature mortality (aged <45 and <30) associated with one standard deviation increase in bone length Table 1 Odds ratios for increase (or decrease) in premature mort
(models controlling for sex alone and for burial phase and sex)

\begin{tabular}{|c|c|c|c|c|c|c|}
\hline & \multicolumn{3}{|c|}{$\begin{array}{l}\text { OR ( }(95 \% \text { CI) of dying before age 30, for a } 1 S D \text { increase in } \\
\text { bone length }\end{array}$} & \multicolumn{3}{|c|}{$\begin{array}{l}\text { OR ( } 95 \% \text { CI) of dying before age } 45 \text {, for a } 1 S D \text { increase } \\
\text { in bone length }\end{array}$} \\
\hline & \multirow[t]{2}{*}{ Controlling for sex } & \multicolumn{2}{|c|}{ Controlling for sex and burial period } & \multirow[t]{2}{*}{ Controlling for sex } & \multicolumn{2}{|c|}{ Controlling for sex and burial period } \\
\hline \multicolumn{5}{|c|}{ Pooled arm, leg and combined long bone index } & & \\
\hline Arm bone index $(n=410)$ & 0.84 & $0.82(0.66$ to 1.02$)$ & $\mathrm{p}=0.08$ & 0.85 & $0.84(0.67$ to 1.05$)$ & $\mathrm{p}=0.13$ \\
\hline Leg bone index $(n=370)$ & 0.84 & $0.85(0.67$ to 1.07$)$ & $\mathrm{p}=0.16$ & 0.91 & $0.93(0.74$ to 1.18$)$ & $\mathrm{p}=0.57$ \\
\hline Combined long bone index $(n=490)$ & 0.80 & $0.80(0.65$ to 0.98$)$ & $\mathrm{p}=0.03$ & 0.84 & $0.84(0.69$ to 1.04$)$ & $\mathrm{p}=0.11$ \\
\hline \multicolumn{7}{|c|}{ Individual bones (number of subjects with available bones) } \\
\hline Femur $(n=293)$ & 0.84 & $0.84(0.66$ to 1.08$)$ & $\mathrm{p}=0.17$ & 0.88 & $0.89(0.70$ to 1.14$)$ & $\mathrm{p}=0.36$ \\
\hline Tibia $(n=284)$ & 0.87 & $0.87(0.68$ to 1.11$)$ & $\mathrm{p}=0.27$ & 0.94 & $0.94(0.73$ to 1.22$)$ & $\mathrm{p}=0.66$ \\
\hline Fibula $(n=96)$ & 0.81 & $0.81(0.54$ to 1.23$)$ & $\mathrm{p}=0.32$ & 1.10 & $1.19(0.75$ to 1.88$)$ & $\mathrm{p}=0.46$ \\
\hline Humerus $(n=341)$ & 0.80 & $0.79(0.64$ to 0.99$)$ & $\mathrm{p}=0.04$ & 0.81 & $0.81(0.64$ to 1.03$)$ & $\mathrm{p}=0.08$ \\
\hline Radius $(n=261)$ & 0.87 & $0.86(0.66$ to 1.11$)$ & $\mathrm{p}=0.26$ & 1.04 & $1.05(0.80$ to 1.38$)$ & $\mathrm{p}=0.72$ \\
\hline Ulna $(n=242)$ & 0.93 & $0.91(0.70$ to 1.20$)$ & $\mathrm{p}=0.51$ & 1.07 & $1.05(0.79$ to 1.40$)$ & $\mathrm{p}=0.73$ \\
\hline
\end{tabular}


bones and for all available leg bones separately. We also produced an index based on the mean of the $\mathrm{z}$ scores for all available long bones. The number of bones contributing to each index varied from subject to subject.

The odds ratios presented are the increase (or decrease) in odds of death at an early age $(<30$ or $<45)$ associated with a one standard deviation increase in long bone length.

\section{Results}

There were 490 sets of remains with complete data on sex, period of burial, approximate age at death and measurement of at least one long bone. Of these 321 (65\%) were male and 169 $(35 \%)$ female, the proportion of female remains was higher in more recent burials. One hundred and seventy eight $(55 \%)$ of men and $123(73 \%)$ of women died before the age of $45 ; 124(39 \%)$ men and $94(56 \%)$ of the women died before 30 . The median age at death was 37 for men and 31 for women. A total of 410 subjects had at least one available arm bone and 370 had at least one available leg bone. There was some evidence of a secular increase in long bone length. Over the years studied radius length increased by $0.2 \mathrm{~cm}$ (95\% CI 0.1 to $0.3 \mathrm{p}<0.01)$ every 200 years, there were similar increases in the length of the tibia $(\mathrm{p}=0.08)$, ulna $(\mathrm{p}<0.01)$ and humerus $(p=0.03)$. Women were more likely to die young than were men. The odds ratio for death before the age of 45 years was 1.94 (95\% CI 1.40 to 2.69 ) in women compared with men.

The associations between long bone length and age at death are given in table 1. For all bones examined the odds ratios for death before the age of 30 decreased as bone length increased, with a one standard deviation increase in bone length associated with a $10 \%$ $20 \%$ decline the risk of premature mortality. These associations reached conventional levels of statistical significance for the combined bone length index $(p=0.03)$ and humerus length $(p=0.04)$ and were of borderline significance in relation to the arm bone index $(p=0.08)$. For death before the age of 45 no consistent pattern was seen, although for the combined arm, leg and long bone indices greater length was associated with a reduced risk of premature mortality. There was no evidence that either a particular long bone or upper compared with lower limb bone length was more strongly associated with premature mortality. We found no evidence that associations between long bone length and premature mortality differed in different burial periods. Likewise, there were no significant interactions between sex and bone length with respect to their effects on mortality and the strength of the associations was similar in men and women.

To check that our findings were not biased by the inclusion of subjects whose growth was incomplete we repeated the analyses without subjects with an estimated age at death of $<25$ years. The odds ratios were essentially unchanged.
KEY POINTS

- Contemporary epidemiological studies indicate that tall people tend to live longer.

- The main causes of death are different today from those in pre-industrial Britain.

- An examination of skeletal remains dating from the 9 th century suggests that stature has been associated with reduced premature mortality for many centuries.

\section{Discussion}

This analysis provides evidence from an archaeological sample that long bone length is associated with age at death-those with smaller bones tend to die younger. There are a number of limitations to this analysis. Firstly, we do not know how representative those with complete remains and buried within this graveyard were of the general population, although we have no reason to believe that the selection processes involved in obtaining our sample will bias the results we have obtained. Secondly, we have no information on the socioeconomic status of the subjects examined here and affluence is generally associated with longevity and greater stature. Thirdly, we do not know the causes of death and so cannot determine whether the stature-mortality associations differ for particular diseases as they do in contemporary populations. ${ }^{2}$ Fourthly, we have examined 18 different bone lengthmortality associations, increasing the likelihood of false positive findings (type I error). However, as many of the bone lengths are intercorrelated we might expect some consistency across the hypothesis tests we have conducted. Lastly, our assessment of age at death is inevitably crude and may be subject to some error, again this error is likely to be nondifferential with respect to long bone length and is most likely to attenuate the associations we have observed.

Height is an indicator of childhood health and nutrition, ${ }^{6}$ so height-mortality associations have been interpreted as suggesting either that exposures in childhood have long term influences on adult health or that those factors leading to poor childhood growth continue to operate and affect health in adulthood. Mechanisms for height-mortality associations in the past may differ from those today, ${ }^{2}$ for example short stature may have increased the risk of death in childbirth and this may account for the higher risk of premature mortality in women. However, short bones, it would appear, have always been a marker of a short life.

The authors would like to acknowledge English Heritage and the Arthritis Research Council for funding aspects of earlier vided ho the data, the two anonymous reviewers who promed of Socil cort列 centre of the MRC Health Services Research Collaboration.

Funding: none.

Conflicts of interest: none 
Waaler HT. Height, weight and mortality: the Norwegian experience. Acta Med Scand 1984;679 (suppl): 1-56.

Davey Suc. Acta Med Scand 1984,679 (suppl):1-56. death among men and women: aetiological implications of associations with cardiorespiratory disease and cance mortality. F Epidemiol Community Health 2000;54:97-103.

3 Mays S, Cox M. Sex determination in skeletal remains. In: Cox M, May S, eds. Human osteology in archaeology and forensic science. London: Greenwich Medical Media, 2000:117-30.
4 Buikstra JE, Ubelaker DH, eds. Standards for data collection from skeletal remains. Fayettville, AR: Arkansas Archaeologifrom skeletal remains. Fayettville, AR: Arka
cal Survey Research Series, 1994:no 44.

5 Cox M. Ageing adults from the skeleton. In: Cox M, May S, eds. Human osteology in archaeology and forensic science. London: Greenwich Medical Media, 2000:61-80.

6 Floud R, Wachter K, Gregory A. Height, health and history. Nutritional status in the United Kingdom, 1750-1980. Cambridge: Cambridge University Press, 1990.

\section{1st Asia Pacific Forum on Quality Improvement in Health Care}

Three day conference

\section{Wednesday 19 to Friday 21 September 2001 Sydney, Australia}

We are delighted to announce this forthcoming conference in Sydney. Authors are invited to submit papers (call for papers closes on Friday 6 April), and delegate enquiries are welcome. The themes of the Forum are:

- Improving patient safety

- Leadership for improvement

- Consumers driving change

- Building capacity for change: measurement, education and human resources

- The context: incentives and barriers for change

- Improving health systems

- The evidence and scientific basis for quality improvement.

Presented to you by the BMJ Publishing Group (London, UK) and Institute for Healthcare Improvement (Boston, USA), with the support of the the Commonwealth Department of Health and Aged Care (Australia), Safety and Quality Council (Australia), NSW Health (Australia), and Ministry of Health (New Zealand).

For more information contact: quality@bma.org.uk or fax +44(0)20 73836869 